www.jmscr.igmpublication.org

Index Copernicus Value: 79.54

ISSN (e)-2347-176x ISSN (p) 2455-0450

crossref DOI: https://dx.doi.org/10.18535/jmscr/v7i5.66

\title{
Surgical Management of Left Ventricle Hydatid Cyst- A Rare Case Presentation
}

\section{Authors \\ Dr Dhananjay Bansal, Dr Rahul Bhushan, Dr Jai Bhagwan, Dr Vijay Kumar Gupta, Dr Vijay Grover}

\section{Introduction}

Hydatid cyst of Heart is rare disease present only in 0.5 to $2 \%$ of all Hydatid disease cases. Early diagnosis and treatment are important as Hydatid cyst of heart carries high risk of rupture.

\section{Case Presentation}

A 19-year-old female with atypical chest pain for eight months was referred to us.

Echocardiography revealed $3.27 \times 3.12 \mathrm{~cm}$ cyst in LV attached to posterior and inferior wall suggestive of Hydatid cyst. Diagnosis confirmed by MRI showing $2.9 \times 3.1 \mathrm{~cm}$ well marginated cystic lesion in inferolateral myocardium of upper portion of left ventricle. Another cyst of $3.4 \times 3.8$ $\mathrm{cm}$ was present in Liver Segment VII

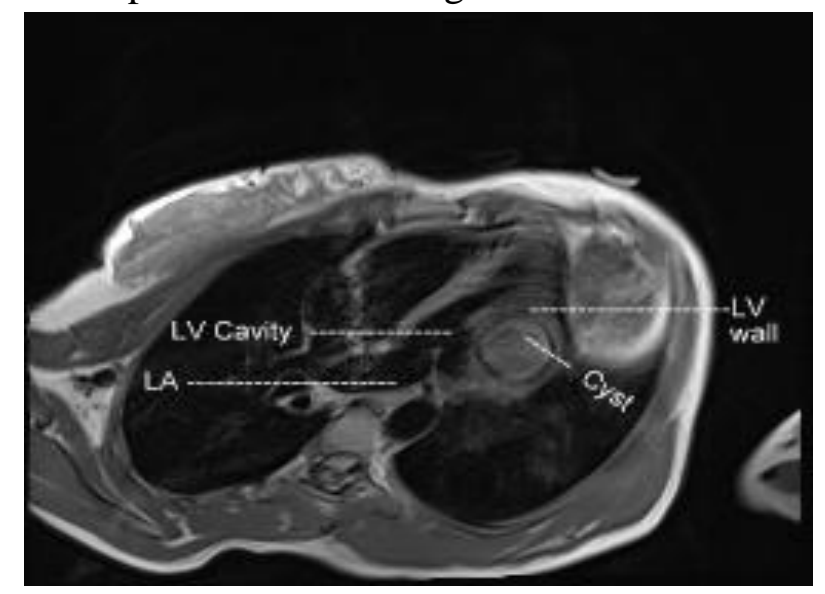

However Hydatid serology turned out to be negative. Via midline sternotomy on pump, Hydatid cyst cavity was opened and contents aspirated without entering LV cavity while protecting against spillage of contents to surrounding areas using Betadine soaked gauge pieces. Hypertonic (3\%) saline used as scolicidal agent and the cyst was enucleated. Residual cavity was closed with ePTFE felt. Post op recovery was uneventful and patient is doing well in follow up. Histopathologic examination confirmed hydatid cyst.

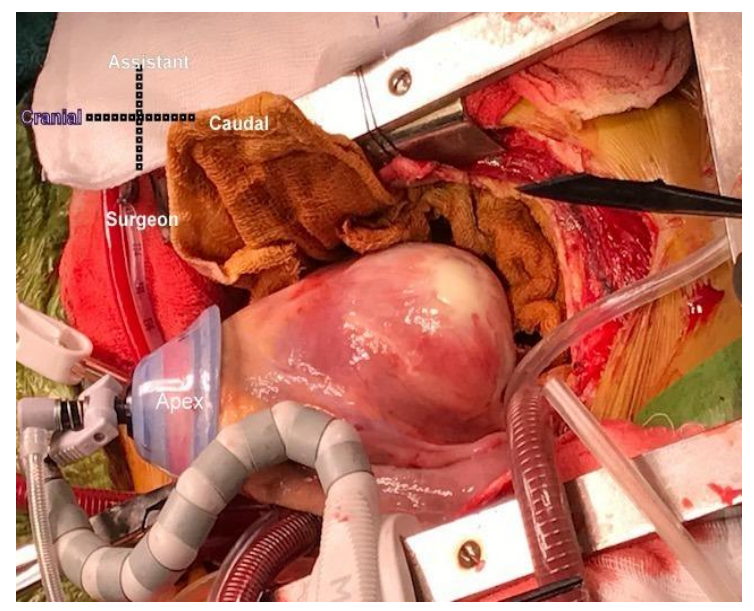



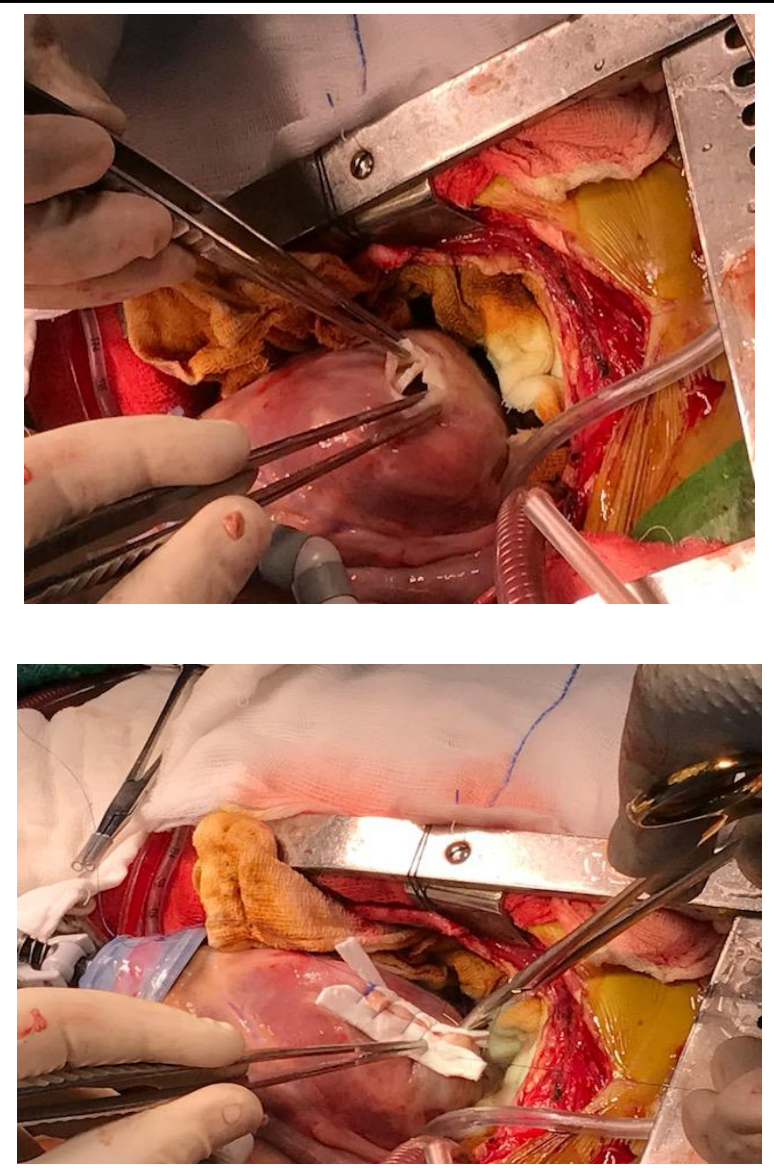

\section{Conclusions}

In myocardial hydatid cysts, we recommend early surgery, via median sternotomy on pump enucleation of cyst without entering the cardiac chambers and avoiding dissemination using scolicidal agents. Residual cavity should be addressed properly to avoid any myocardial dysfunction. 